\title{
Best Skin Suture: Interrupted or Continuous?
}

\author{
Parinaz Shahroudi', Moslem Armoeyan*1 and Shayan Alijanpour ${ }^{2,3}$ \\ ${ }^{1}$ MSc student of Surgical Technology, Faculty of Nursing and Midwifery, Iran \\ ${ }^{2}$ MSc student of Critical Care Nursing, Faculty of Nursing and Midwifery, Iran \\ ${ }^{3}$ Education, Research and Planning, Prehospital Emergency Organization and Emergency Medical Service Centre, Iran \\ *Corresponding author: Moslem Armoeyan, MSc student of Surgical Technology, Student Research Committee, Faculty of \\ Nursing and Midwifery, Isfahan, Iran
}

\begin{abstract}
ARTICLE INFO
Received: 慧 May 14, 2019

Published: 㠈 May 21, 2019

Citation: Parinaz Shahroudi, Moslem Armoeyan, Shayan Alijanpour. Best Skin Suture: Interrupted or Continuous? Biomed J Sci \& Tech Res 18(2)-2019. BJSTR. MS.ID.003119.
\end{abstract}

Keywords: Skin Closure; Suture Technique; Wound Closure Techniques; Sutures

\begin{abstract}
Introduction: Suturing type is important because impaired wound healing can increase the cost of the treatment. According to the controversy in the studies regarding the surgeon's opinion, current study was conducted.
\end{abstract}

Method: This review study was conducted with key words that include of sutures, interrupted, continuous, surgery, surgeons in data bases such as google scholar, web of sciences, pubmed, embase, science direct between 2015 to 2019. Inclusion criteria include of randomized clinical trials, English language study. 19 studies were included. If study not compared two methods of continuous and separate skin suture were excluded.

Results: In three studies, there was no difference between the two suture methods. In Ahmad et al. study, Visual Analog Scoring was a measure of pain on the third day after surgery. 5 cases $(12.5 \%)$ of continuous group and 23 cases $(57.5 \%)$ of separated groups reported pain. In Maged et al. study showed that complications such as hematoma $(\mathrm{p}=$ $0.04)$, infection $(p=0.008)$ need for re-closure $(p=0.004)$, were higher in the continuous group. There was no difference in the formation of colloid between the two groups. The suture with the separate method prolonged the operation time, but it was not significant $(\mathrm{p}<0.14)$.

Conclusion: Results did not show the difference between two sutures in term of pain and scar width, although the satisfaction of patients with continuous sutures was higher and the use of continuous sutures in clean wounds that are not tension, can have better results.

\section{Introduction}

Most surgical procedures require a skin cut to access the surgical site [1]. There are several methods for closing surgical wounds. For example, the use of suture, stapler, tape and tissue adhesives can be mentioned [2]. Skin sutures can be continuous or separated. Typically, continuous sutures are subcuticular, while the interrupted sutures involve the full thickness of the skin [3,4]. Both of them can be absorbable or non-absorbable [5]. Absorbable sutures do not require removal, therefore, can reduce anxiety of patient postoperatively [6]. Suture techniques and their complications can affect the beauty of the Surgery site. If sutured correctly, it can close the edges of the wound by removing the dead space between the tissues [7]. Impaired wound healing can increase the cost of the treatment and reduce the beauty of the cutting site [8]. According to the controversy in the studies regarding the surgeon's opinion, current study was conducted.

\section{Method}

This study was conducted with key words that include of sutures, interrupted, continuous, surgery, surgeons in data bases such as google scholar, web of sciences, pubmed, embase, sciencedirect between 2015 to 2019. Inclusion criteria include of randomized clinical trials, English language study. 19 study was included, and two authors read abstract carefully and if study not compared two methods of continuous and separate skin suture were excluded. Finally, five articles were selected for this research. Informed consent not recommended in review article. 


\section{Results}

In Liu X et al. study, seventy-three subjects were in the separated suture group and sixty-nine in the continuous suture group. the Measuring tool was the patient's and observer's evaluation in 12 months after surgery. There was no difference between the two suture methods. Often, hyper or hypoesthesia observed in continuous suture group [9]. In Javadi study, comparison of two methods of Suture techniques in Appendectomy surgery in 2017 was done in Iran. There were thirty-five people in each group. Patients were evaluated on the first, seventh, thirty, ninety days after the operation. There was no difference between the two groups in terms of severity of pain and scar. Only at the end of the seventh day in the continuous group, the severity of pain and the extent of scar were found to be lower. More satisfaction was observed in the continuous group in wound healing and scar compared to the interrubted group [10]. In Ahmad study, comparison of two continuous and separated methods of Suture techniques in open Cholecystectomy was conducted in Pakistan in 2018. Forty subjects were in each group. VAS (Visual Analog Scoring) was a measure of pain on the third day after surgery. $5(12.5 \%)$ of the patients from the continuous group and 23 (57.5\%) of the patients from the separated groups Reported pain. The satisfaction of the continuous group was higher [11].

In Som et al. study, that was investigated the episiotomy repair surgery in Indian women showed that there were 32 people in each group. A visual analogue scoring (VAS) test was used to measure pain from 12 to 18 hours after episiotomy and 10 days postpartum. It was also used to assess the amount of wound healing from the REEDA scale (redness, edema, ecchymosis, drainage, proximity to the edges). No significant difference was observed between the two groups [12]. In Maged et al. study, that was conducted on obese women after cesarean section surgery in Egypt, finding showed that complications such as hematoma ( $p=0.04)$, infection ( $p=0.008)$, need for re-closure $(p=0.004)$, were higher in the continuous group than the interrupted group. There was no difference in the formation of colloid and serum between the two groups. The suture with the separate method prolonged the operation time, but it was not significant $(\mathrm{p}<0.14)$ [13].

\section{Conclusion}

The review of the study did not show the difference between the use of continuous and separated suture in term of consequences, such as pain and scar width, although the satisfaction of patients with continuous sutures was higher. A study of the incidence of infection, hematoma, and the need for re-closure of the wound was reported further in the continuous procedure. So, it can be said that the use of continuous sutures in clean wounds that are not tension, can have better results.

\section{References}

1. Walton RB, Shnaekel KL, Ounpraseuth ST, Napolitano PG, Magann EF, et al. (2019) High transverse skin incisions may reduce wound complications in obese women having cesarean sections: a pilot study. The Journal of Maternal-Fetal \& Neonatal Medicine 32(5): 781-785.

2. Ananda BB, Vikram J, Ramesh BS, Khan HM, (2019) A comparative study between conventional skin sutures, staples adhesive skin glue for surgical skin closure. International Surgery Journal 6(3): 775-782.

3. Al-Mubarak L, Al-Haddab M (2013) Cutaneous wound closure materials: an overview and update. Journal of cutaneous and aesthetic surgery 6(4): 178.

4. Sklar LR, Pourang A, Armstrong AW, Dhaliwal SK, Sivamani RK, et al. (2019) Comparison of Running Cutaneous Suture Spacing During Linear Wound Closures and the Effect on Wound Cosmesis of the Face and Neck: A Randomized Clinical Trial. JAMA dermatology 155(3): 321-326.

5. Gurusamy KS, Toon CD, Allen VB, Davidson BR (2014) Continuous versus interrupted skin sutures for non-obstetric surgery. Cochrane Database of Systematic Reviews 14(2).

6. Kundra RK, Newman S, Saithna A, Lewis AC, Srinivasan S, et al. (2010) Absorbable or non-absorbable sutures? A prospective, randomised evaluation of aesthetic outcomes in patients undergoing elective day-case hand and wrist surgery. The Annals of The Royal College of Surgeons of England 92(8): 665-667.

7. Zhai M, Zhang YA, Wang ZY, Sun JH, Wen J, et al. (2016) A randomized controlled trial comparing suture-fixation mucopexy and Dopplerguided hemorrhoidal artery ligation in patients with grade III hemorrhoids. Gastroenterology research and practice 2016.

8. Gurusamy KS, Toon CD, Allen VB, Davidson BR (2014) Continuous versus interrupted skin sutures for non-obstetric surgery. Cochrane Database of Systematic Reviews 14(2).

9. Liu X, Nelemans PJ, Frenk LD, Sengers H, Tuinder SM, et al. (2017) Aesthetic outcome and complications of simple interrupted versus running subcuticular sutures in facial surgery: A randomized controlled trial. Journal of the American Academy of Dermatology 77(5): 911-919.

10. Javadi SM, Kasraianfard A, Ghaderzadeh P, Khorshidi HR, Moein A, et al. (2018) Comparison of subcuticular and interrupted suturing methods for skin closure after appendectomy: A randomized controlled trial. Iranian Red Crescent Medical Journal 20(1).

11. Ahmad M, Mushtaq A, Ahmad M, Uddin Afridi Z (2018) Comparison of subcuticular versus interrupted sutures in open cholecystectomy right subcostal incision. Pak J Surg 34(4): 308-312.

12. Som B, Srirupa B (2017) Interrupted versus subcutaneous continuous skin suture in Episiotomy Repair in Indian urban women: A Study. International Journal of Surgery \& Surgical Techniques 1(2): 000107.

13. Maged AM, Mohesen MN, Elhalwagy A, Abdelaal H, Almohamady M, et al. (2018) Subcuticular interrupted versus continuous skin suturing in elective cesarean section in obese women: a randomized controlled trial. The Journal of Maternal-Fetal \& Neonatal Medicine p. 1-6. 


\section{ISSN: 2574-1241}

DOI: 10.26717/BJSTR.2019.18.003119

Moslem Armoeyan. Biomed J Sci \& Tech Res

(C) This work is licensed under Creative

Submission Link: https://biomedres.us/submit-manuscript.php

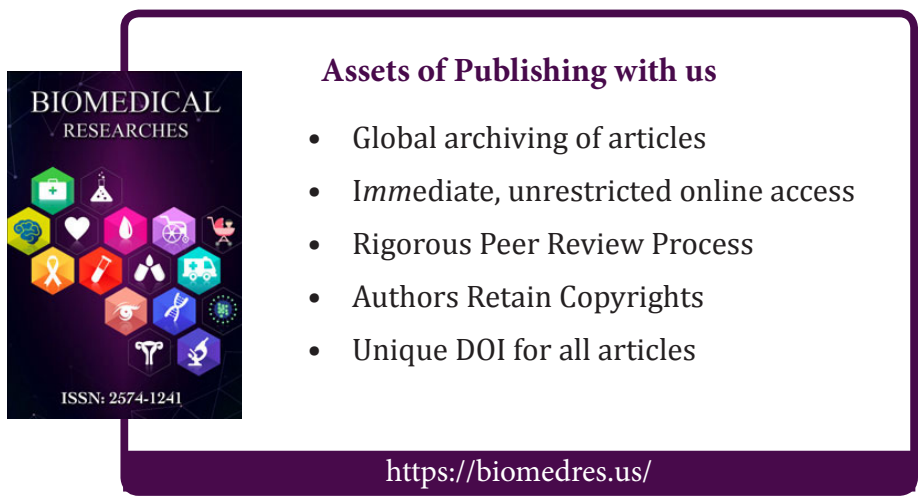

